\title{
Rancang Bangun Tacho Generator Sebagai Sensor Kecepatan Pada Praktikum Kendali Motor-Motor Listrik
}

\author{
Oleh: \\ Roswaldi Sk, Julsam ${ }^{1)}$ \\ Hendra Suhendri, Rafki Chandra, Didi Kurniawan ${ }^{2)}$ \\ ${ }^{1)}$ Staf Pengajar Teknik Elektro Politeknik Negeri Padang \\ ${ }^{2)}$ Alumni Teknik Elektro Politeknik Negeri Padang
}

\begin{abstract}
The research implementing "Tachogenerator as the sensor for controller of Electric Motor Speed rotation at electric laboratories"

Plant (Object controlled) is controlled by the electric motors speed rotation in $A C$ or DC, by setting armature voltage of motor using digital PID controller and fuzzy logic from Personal Computer (PC). Although the load disturbances are changing significantly, but the motor speed rotation can be stabilized by feedback input from tachogenerator which are the focus in this research.

PID controller dan fuzzy Logic controller applications are used to find the advantages the disadvatages or controll methode of motor reliability in dinamic controll (speed rotation) which cause the system more stabil. The result can be seen in maintained system responses and the system reliabilty against disturbances.
\end{abstract}

Keyword: PID controller, Fuzzy Logic Controller, Tachogenerator, Rotation Setting, Electric Motor.

\section{PENDAHULUAN}

Kendali mesin arus searah (MAS) dan mesin arus bolak balik (MABB) adalah mata kuliah praktek yang diberikan pada tingkat dua dan tiga. Diberikannya mata kuliah ini sudah sesuai dengan kemajuan teknologi di industri Tetapi muncul permasalahan dengan peralatan yang dimiliki program studi listrik yang kurang menunjang untuk dijalankan secara benar sesuai dengan kurikulum. Sudah banyak usaha yang dilakukan misalnya peremajaan alat dengan dana rutin Politeknik yang terbatas, dana kompetisi (TPSDP) batch III tetapi tidak lulus. Alternative lain adalah memberikan dana penelitian kepada staf pengajar untuk merancang bangun alat praktek yang sesuai dengan kebutuhan tersebut.

Melalui dana penelitian semi-que V tahun anggaran 2004 (final), kami bersama tim mencoba memberikan solusi terhadap masalah diatas dengan membuat alat sensor kecepatan (tachogenerator) yang sangat dibutuhkan pada praktek mesin-mesin listrik.

Praktek kendali MAS dan MABB membutuhkan sejumlah sensor untuk pengaturan sistemnya, tetapi Politeknik saat ini hanya memiliki satu buah sensor kecepatan (tachogenerator) yang dipakai untuk satu kelas selama praktek sehingga tujuan pembelajaran tidak tercapai. Untuk itu perlu penambahan peralatan tersebut. 
Hasil penelitian yang diharapkan adalah relevan dengan materi praktikum laboratorium kendali mesin-mesin listrik sehingga menjadi nilai tambah berupa peralatan dan materi praktikum di laboratorium kendali mesin-mesin listrik jurusan teknik elektro ( lingkup kegiatan point $B$ ).

Berikut gambaran proyek penelitian yang akan dilakukan yaitu berupa modul "Tachogenerator"

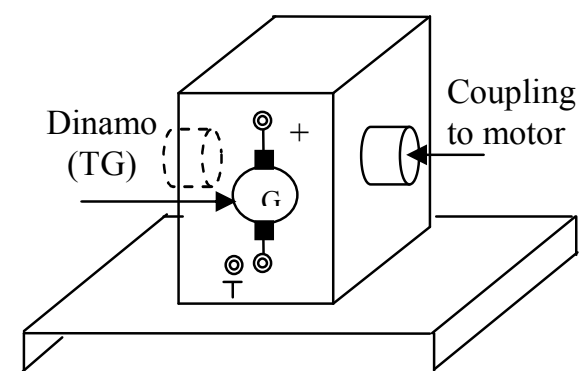

Gambar 1. Ilustrasi Rancangan Penelitian "Tachogenerator"

\section{Perumusan Masalah}

Berdasarkan latar belakang dan tujuan penelitian maka dapat dirumuskan dan di-justifikasi permasalahannya sebagai berikut:

1. Bagaimana meningkatkan materi mata kuliah teori dan praktikum kendali mesin-mesin listrik yang mencapai sasaran learning outcomes berorientasi objek dapat diwujudkan.

2. Bagaimana mengembangkan peralatan praktek labor mesin-mesin listrik yang masih kurang dan belum setara dengan kemajuan teknologi di industri.

3. Bagaimana teknik mengajarkan materi praktek kendali mesin-mesin listrik yang sepadan dengan yang ada di industri walaupun itu dalam skala labor.

4. Apakah dengan penelitian relevansi "Rancang Bangun Tacho Generator sebagai Sensor Kecepatan pada Praktek Kendali Motor-Motor Listrik" akan dapat mengatasi permasalahan tersebut?

\section{METODE PENELITIAN}

Agar dicapainya sasaran learning outcomes seperti yang diharapkan maka langkah atau metodologi yang ditawarkan adalah:

1. Studi literatur yang materinya berkaitan langsung dengan usulan kegiatan penelitian

2. Metoda diskusi dengan rekan satu tim penelitian untuk mencari solusi yang lebih effisien

3. Metoda pendekatan antara teori dan praktek dengan mengadakan percobaan di laboratorium

4. Metoda pengujian yaitu dengan menguji karakteristik alat yang dibuat dan dibandingkan dengan teori-teori yang menunjang rancangan sistem penelitian.

\section{Hasil yang diharapkan}

1. Sebuah "tachogenerator" sebagai salah satu sensor kecepatan yang nantinya dapat digunakan untuk praktek labor kendali mesin-mesin listrik.

2. Tambahan modul kendali mesinmesin listrik yang difokuskan pada pengaturan kecepatan putaran motor dc, yang berorientasi objek yang sesuia dengan kondisi di industri.

3. Job sheet praktikum kendali mesin listrik dengan plant pengaturan kecepatan putaran motor dc

\section{Pelaksanaan kegiatan}

1. Pengumpulan informasi data bahan dan peralatan

2. Menyiapkan bahan penelitian

3. Menyiapkan alat dan instrumen penelitian

4. Pembelian bahan atau komponen penelitian

5. Pembuatan/perakitan komponen Hardware dan Software

6. Menyusun rancangan penelitian : 
- Melakukan uji penelitian di Laboratorium mesin-mesin listrik jurusan teknik elektro Politeknik Universitas Andalas Padang

- Variabel yang di uji adalah rangkaian kendali analog/digital, interface, rangkaian driver dan sensor kecepatan

- Pengujian rangkaian kendali menggunakan plant motor DC

- Metoda penelitian adalah metoda percobaan dan metoda perbandingan yaitu kendali PID Digital dan Fuzzy Logic dengan plant motor DC.

a. Membuat tahapan laporan penelitian sesuai kesepakatan jadwal.

\section{HASIL PENELITIAN}

\section{Perancangan Perangkat Keras}

\section{Tacho Generator (Sensor)}

Pembuatan Tacho Generator ini berdasarkan pada sample yang ada pada labor, sehingga ukuran dari tacho ini sama dengan yang aslinya.

Tacho Generator berfungsi sebagai sensor kecepatan dari motor DC yang akan memberi sinyal analog ke PC melalui interface berupa Analog Digital Converter (ADC) .

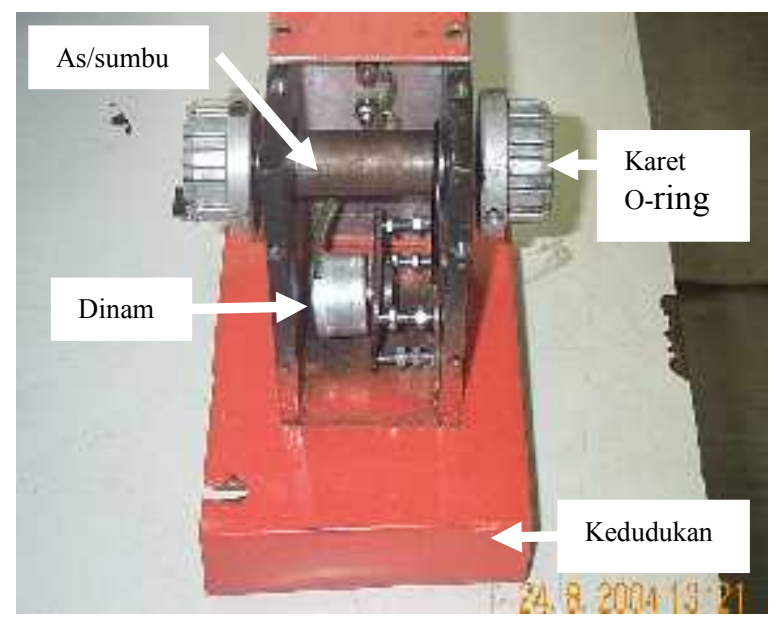

Gambar 2. Konstruksi Tacho Generator
2. Interface Parallel Port

Parallel port adalah media penghubung antara rangkaian analog ke rangkaian digital melalui ADC 0804 dan dari digital ke analog melalui DAC 0808. Pemakaian alamat pin dari parallel port untuk analog digital converter dan digital analog converter, sesuai gambar dibawah ini :

3. ADC 0804 (Analog Digital Converter) IC ADC 0804 inilah yang mengubah sinyal analog keluaran dari tacho generator sebagai sensor kecepatan motor DC menjadi sinyal digital yang akan dibaca oleh PC untuk diproses sesuai kebutuhan.

4. DAC 0808 (Digital Analog Converter) IC 0808 ini dipakai untuk mengubah sinyal digital keluaran dari PC telah diolah dari masukkan sinyal analog ADC sehingga menjadi sinyal analog.

5. Driver (Actuator)

Driver merupakan penggerak motor DC yang berdaya besar dengan memberikan input konstan pada motor. Rangkaian Driver ini berfungsi sebagai input tegangan dari DAC ke motor. Nilai tegangan inputnya adalah variabel. Dengan memvariabelkan nilai pada DAC, maka tegangan pada tahanan medan $(V t)$ dari motor juga variabel sehingga kecepatan putar dari motor juga berubah-ubah.

6. Penyearah

Penyearah adallah komponen pendukung untuk tegangan catu bagi ADC sebesar 5 Volt DC dan DAC yang memerlukan tegangan $\mathrm{Vcc}$ sebesar 5 Volt Dc dan tegangan Vee sebesar - 15 Volt DC, serta juga untuk tegangan konstan bagi driver sebesar 220 Volt DC. Jadi disini dibutuhkan tegangan AC sebesar 220 Volt untuk membuat tegangan yang lebih kecil dengan menggunakan rangkaian dibawah ini : 
7. Rangkaian lengkap

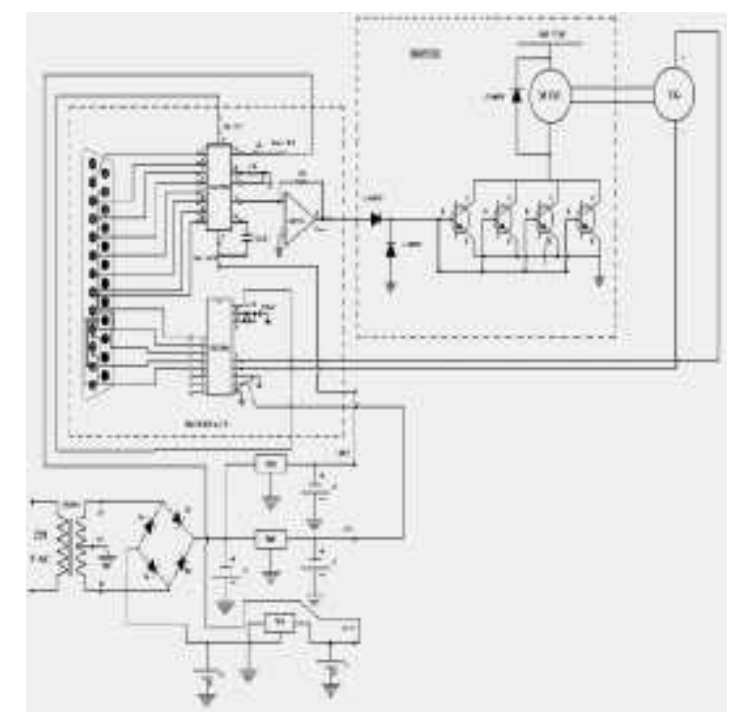

Gambar 3. Diagram Rangkaian Keseluruhan

\section{Perancangan perangkat lunak}

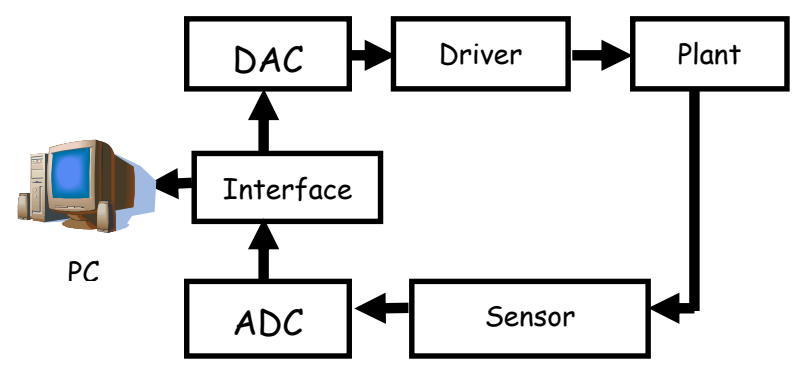

Gambar 4. Diagram Blok Pengontrolan Kecepatan Motor DC

\section{Flow Chart Pengendali PID digital}

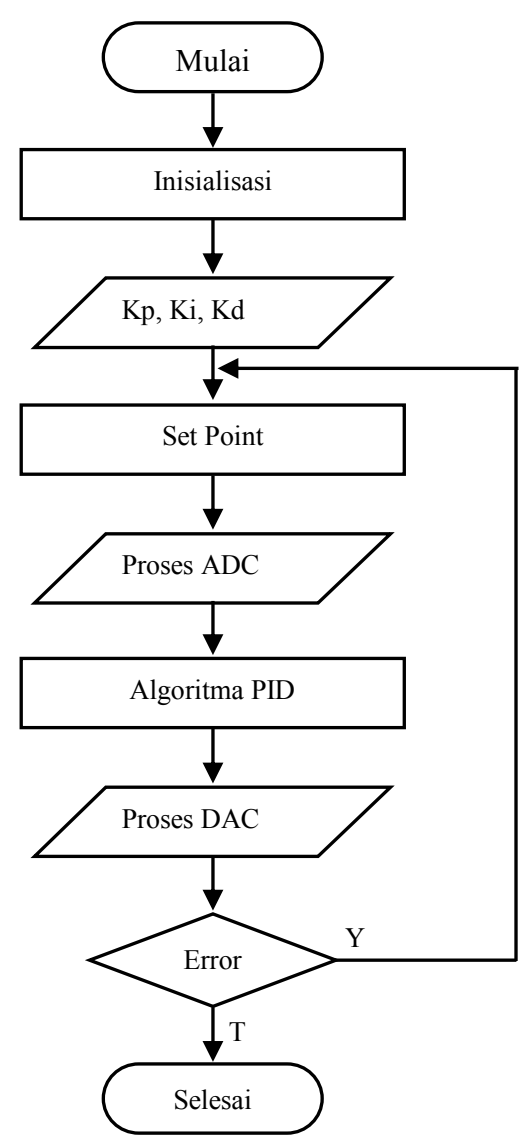

Gambar 5 Flow Chart Pengendali PID Digital

\section{Listing Program Pengendali PID Digital}

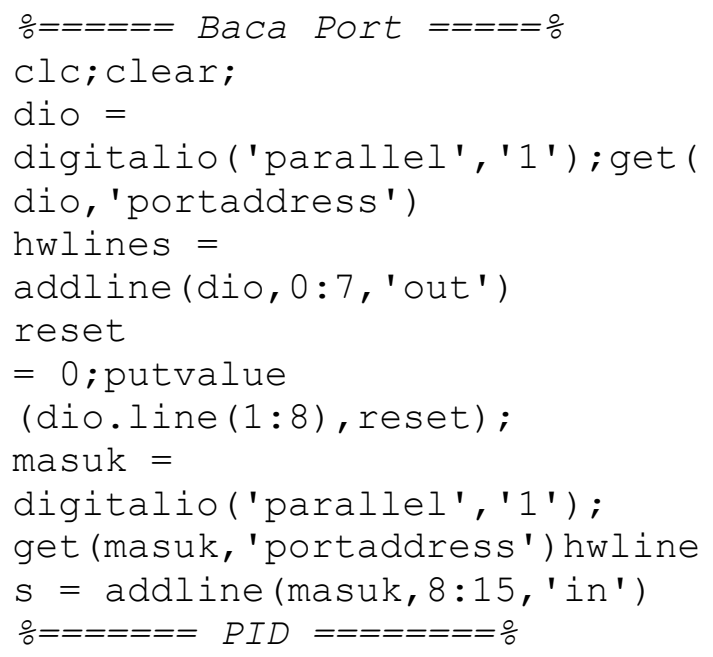




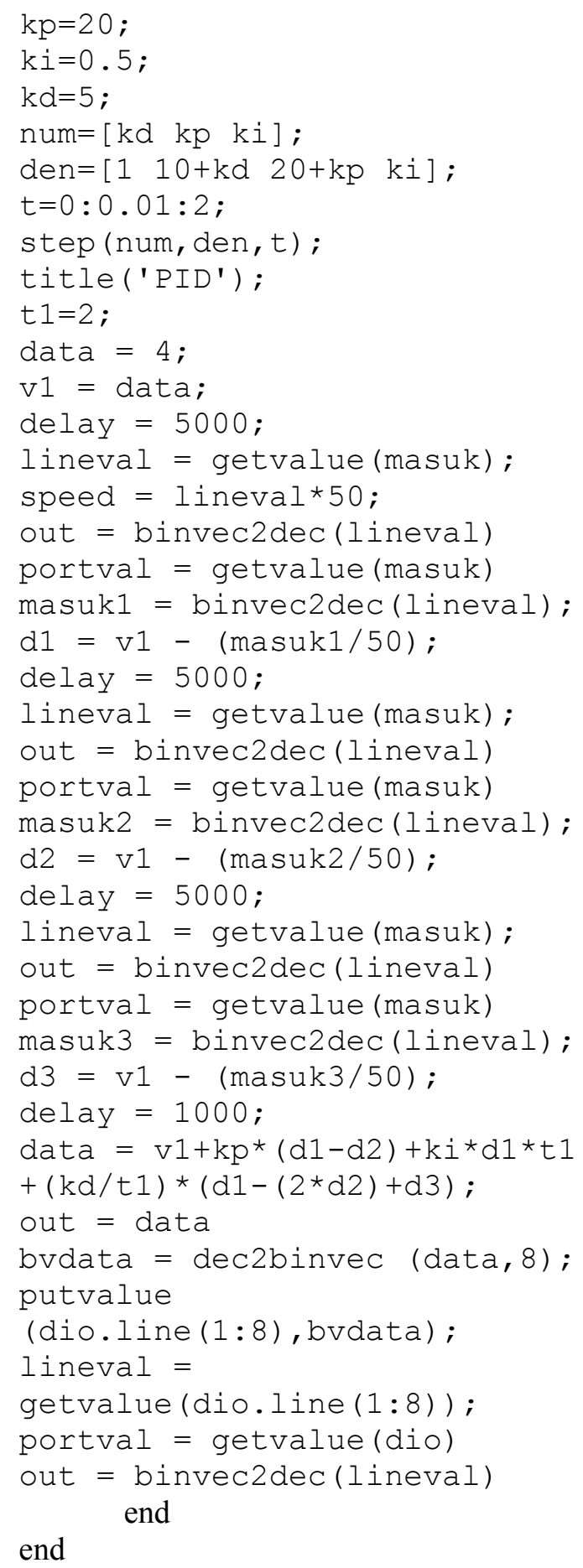

\section{Algoritma Pengendalian Metoda Logika Fuzzy}

1. Melakukan inisialisasi awal.

- mendefinisikan fungsi keanggotaan.

- mendefinisikan aturan (rule base).

- menginisialisasi c [k-1], c[k-2], $\mathrm{u}[\mathrm{k}-1], \mathrm{u}[\mathrm{k}-2]=0$.

2. Menginisialisasi interface $\mathrm{A} / \mathrm{D}-\mathrm{D} / \mathrm{A}$ card.
3. Memasukan set-point dan iterasi.

4. Mendapatkan error, yaitu set-point - $\mathrm{c}[\mathrm{k}]$.

5. Mendapatkan delta error, yaitu $\mathrm{e}[\mathrm{k}]-\mathrm{e}[\mathrm{k}-1]$.

6. Melakukan proses fuzzifikasi.

- Menghasilkan derajat keanggotaan error, \{Grade_E[k]\}.

- Menghasilakn derajat keanggotaan delta error, \{Grade_dE[k]\}.

7. Melakukan proses Inference, yaitu Grade_E[k]* Grade_dE[k].

8. Melakukan proses defuzzyfikasi,

9. Dengan COA sehingga diperoleh $\mathrm{u}[\mathrm{k}]$.

10. Memasukkan variabel $\mathrm{u}[\mathrm{k}] \quad \mathrm{ke}$ persamaan plant dan dihasilkan $\mathrm{c}[\mathrm{k}]$.

11. Mengirim $\mathrm{u}[\mathrm{k}]$ kepersamaan plant untuk simulasi.

12. Menampilkan hasil pada layar, yaitu $\mathrm{c}[\mathrm{k}], \mathrm{E}[\mathrm{k}], \mathrm{dE}[\mathrm{k}]$ dan iterasi.

13. Mengulangi proses jika ingin merubah setpoint dan iterasi.

\section{Perencanaan Software Logika Fuzzy}

Dalam Perencanaan Kendali Hybrid PID-fuzzy, sistem utama tetap menggunakan kendali PID, sedangkan logika fuzzy disini berfungsi untuk memperbaiki respon.

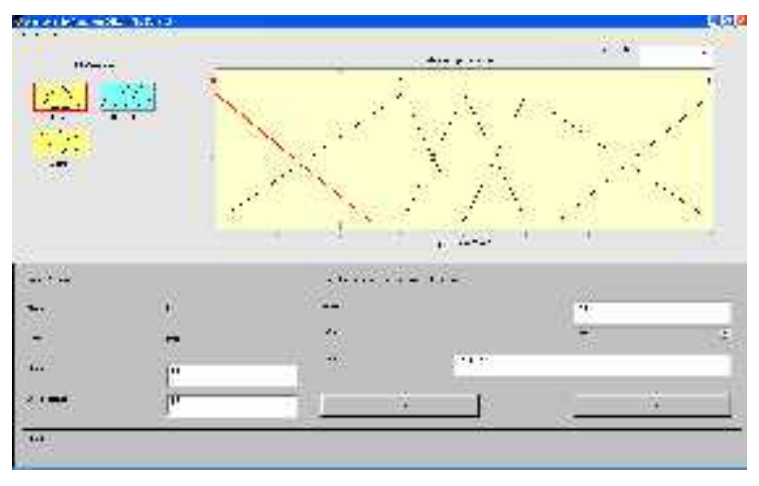

Gambar 6. Membership Function Error dan DError untuk Hybrid

Sistem kendali ini merupakan gabungan/hasil penjumlahan dari output yang dihasilkan oleh kendali PID dengan kendali logika fuzzy. Perbedaan yang 
ada disini yaitu terletak pada rule logika fuzzy dan bentuk membership functionnya, dimana rule ini tidak seperti pada rule fuzzy pada umumnya. Bentuk membership function pada sistem hybrid lebih lebar dari pada bentuk membership function pada logika fuzzy dengan tujuan supaya dapat meredam disturbance dengan cepat. Sedangkan membership output-nya sama seperti membership function pada logika fuzzy.

Tabel 1. Rules untuk kendali Hybrid PID - Logika Fuzzy

\begin{tabular}{c|c|c|c|c|c|c|}
\multicolumn{1}{c|}{} & \multicolumn{1}{c|}{ Error } \\
\hline & NB & NS & G & PS & PB \\
\hline NB & NB & NB & NM & NB & NM \\
\hline dError & NS & NB & NB & NS & G & NM \\
\cline { 2 - 7 } & G & NS & G & G & G & PS \\
\cline { 2 - 7 } & PS & PM & G & PS & PB & PB \\
\cline { 2 - 8 } & PB & PB & PB & PM & PB & PB \\
\hline
\end{tabular}

Keterangan:

$\mathrm{NB}=$ Negative Big

$\mathrm{NS}=$ Negative Small

$\mathrm{G}=$ Good

PS = Positive Small

$\mathrm{PB}=$ Positive Big

$\mathrm{NM}=$ Negative Medium

$\mathrm{PM}=$ Positive Medium

\section{EVALUASI HASIL PELAKSANAAN KEGIATAN}

\section{Deskripsi Kerja Rangkaian}

1. Motor DC disuplai oleh sumber terpisah yaitu sumber tegangan DC $220 \mathrm{~V}$

2. Kecepatan motor DC dikendalikan oleh PID Controller menggunakan program MATLAB.

3. Sensor kecepatan yaitu tacho Generator memberikan masukan ke PID Controller melalui ADC 0804 berupa tegangan variabel maksimal 5 Volt DC.
4. Sinyal analog yang diberikan oleh Tacho generator, diubah oleh ADC 0804 menjadi sinyal digital, selanjutnya diproses melalui interface port parallel.

5. Kemudian sinyal yang telah diolah dikeluarkan kembali dalam bentuk digital melalui port parallel dan disampaikan ke DAC sehingga sinyal tersebut berubah menjadi sinyal analog.

6. Sinyal-sinyal digital PID Controller diteruskan ke driver motor melalui DAC 0808 yang selanjutnya akan menggerakkan motor.

7. Perubahan kecepatan motor dapat diubah-ubah melalui program PID Controller yang telah diprogram pada komputer.

8. Perubahan kecepatan dapat dideteksi oleh sensor (tacho generator), selanjutnya sensor memberikan informasi ke kontrol untuk menstabilkan kecepatan kembali dan begitu seterusnya.

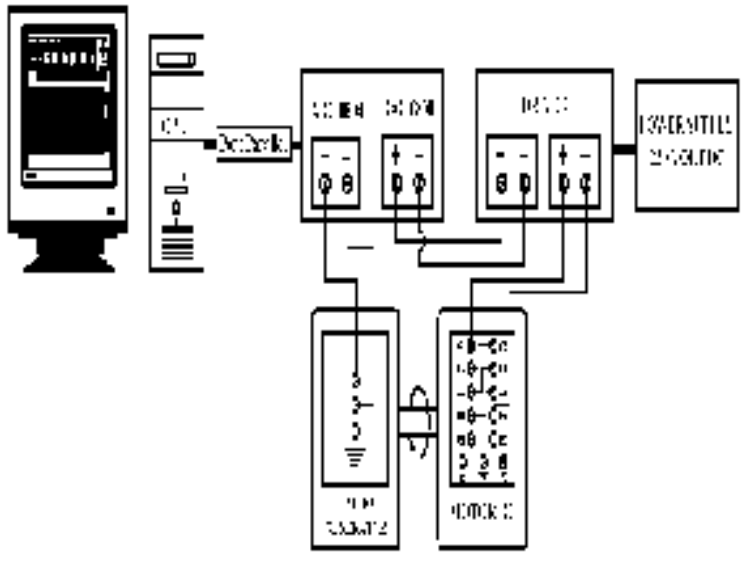

Gambar 7. Blok Diagram Sistem Operasi

\section{PENGUJIAN SISTEM}

Langkah-langkah pengujian dan analisis yang dilakukan dalam pengontrolan kecepatan motor DC menggunakan PC pada penelitian ini adalah: 
1. Pengujian Tacho generator dengan motor.

2. Pengujian ADC 0804 secara manual berdasarkan perhitungan.

3. Pengujian DAC 0808 secara manual berdasarkan perhitungan.

4. Pengujian interface parallel port berdasarkan alamat pin-nya.

5. Pengujian driver sebeagai penggerak motor DC.

6. Pengujian program untuk memanggil alamat pada parallel port.

Tabel 2. Hasil Pengujian Sensor "Tachogenerator"

\begin{tabular}{|c|c|c|}
\hline $\begin{array}{c}\mathbf{V}_{\text {мотоR }} \\
\text { (Volt) }\end{array}$ & $\begin{array}{c}\mathbf{N}_{\text {мотоR }} \\
(\mathbf{r p m})\end{array}$ & $\begin{array}{c}\mathbf{V}_{\text {TG }} \\
(\mathbf{V o l t})\end{array}$ \\
\hline 15,5 & 270 & 0,5 \\
\hline 18 & 532 & 1 \\
\hline 24 & 798 & 1,5 \\
\hline 30 & 1062 & 2 \\
\hline 38 & 1295 & 2,5 \\
\hline 51 & 1560 & 3 \\
\hline 104 & 1799 & 3,5 \\
\hline 227 & 2010 & 4 \\
\hline
\end{tabular}

Dari tabel 2. diatas dapat dibandingan antara besarnya putaran motor dengan tegangan yang dikeluarkan tacho generator. Rata-rata keluaran tacho generator pada saat 1 Volt DC dihasilkan putaran sebesar $500 \mathrm{rpm}$. Jadi bisa dikatakan pada saat 1 Volt dihasilkan putaran $500 \mathrm{rpm}$, saat 2 Volt dihasilkan putaran $1000 \mathrm{rpm}$ begitu seterusnya sampai mencapai kecepatan maksimum dari motor DC yang dipergunakan.

\section{Pengujian Parallel Port}

Untuk keperluan uji-coba, kita bisa menghubungkan LED (Light Emitting Diode) lewat resistor $220 \mathrm{ohm}$, langsung dihubungkan ke pin output dari parallel port. Bisa juga hanya dengan mengukur tegangan 5 volt yang timbul, saat data port dalam keadaan high (TTL high). Tetapi perlu diperhatikan tegangan yang keluar dari parallel port 5 volt, sedangkan arusnya sangat kecil yaitu $4 \mathrm{~mA}$ pada logic 1 dan $-0.4 \mathrm{~mA}$ pada logic nol. Nilai arus negative artinya sink ke dalam parallel port.

\section{Pengujian Analog Digital Converter 0804}

Untuk mengetahui bahwa ADC 0804 bekerja ditandai dengan hidupnya lampu LED apabila bernilai " 1 " dan LED mati apabila bernilai " 0 ". Output dari ADC 0804 bernilai " 1 " atau bernilai " 0 " berdasarkan variable input masuk yang diberikan. Input masuk yang diberikan variable dari 0 --- 5 Volt DC, jadi pada setiap kenaikkan beberapa volt maka akan terjadi perubahan pada ouput dalam bentuk bilangan biner yaitu 00000000 atau 11111111.00000000 pada saat input masuk bernilai nol dan 11111111 pada saat input masuk bernilai $5 \mathrm{~V}$ DC.

Tabel 3. dibawah ini merupakan hasil percobaan yang dilakukan dengan memvariabelkan tegangan input masuk dari 0 volt sampai 5 volt dengan kenaikkan step 0,5 Volt.

Table 3 . Hasil Pengukuran ADC 0804 dengan LED

\begin{tabular}{|c|c|c|c|c|c|c|c|c|c|}
\hline \multirow{2}{*}{$\begin{array}{l}V_{\text {IN }} \\
\text { (V) }\end{array}$} & \multicolumn{8}{|c|}{ Data Biner (Output ADC 0804) } & \multirow{2}{*}{$\begin{array}{c}\text { Data } \\
\text { Desim } \\
\text { al }\end{array}$} \\
\hline & $\begin{array}{l}D \\
7\end{array}$ & D & $\begin{array}{l}D \\
5\end{array}$ & $\begin{array}{l}D \\
4\end{array}$ & - & $\begin{array}{l}D \\
2\end{array}$ & $\begin{array}{l}D \\
1\end{array}$ & I & \\
\hline 0,5 & 0 & 0 & 0 & 1 & & 1 & 1 & & 23 \\
\hline 1 & 0 & 0 & 1 & 1 & & 0 & 1 & & 50 \\
\hline 1,5 & 0 & & 0 & 0 & & 1 & 0 & & 72 \\
\hline 2 & 0 & 1 & 1 & 0 & & 1 & 0 & & 102 \\
\hline 2,5 & 0 & & 1 & 1 & & 1 & 0 & & 125 \\
\hline 3 & 1 & 0 & 0 & 1 & & 1 & 1 & & 150 \\
\hline 3,5 & 1 & 0 & 1 & 1 & & 0 & 1 & & 178 \\
\hline 4 & 1 & 1 & 0 & 0 & & 0 & 0 & & 200 \\
\hline 4,5 & 1 & 1 & 0 & 1 & & 1 & 1 & & 215 \\
\hline 5 & 1 & 1 & 1 & 1 & 1 & 1 & 1 & 1 & 255 \\
\hline
\end{tabular}

Sedangkan melalui perhitungan untuk output ADC 0804 dapat 
dipergunakan persamaan yang telah dibahas di bagian sebelumnya yaitu:

$$
\begin{aligned}
& \text { Konstanta ADC } 0804 \\
& =\frac{1}{255} \times 5=0,019607 \text { Volt }
\end{aligned}
$$

\begin{tabular}{|c|c|c|c|c|c|c|c|c|c|}
\hline \multirow{2}{*}{$\begin{array}{l}V_{\text {IN }} \\
\text { (V) }\end{array}$} & \multicolumn{8}{|c|}{ Data Biner (Output ADC 0804) } & \multirow{2}{*}{$\begin{array}{l}\text { Data } \\
\text { Desi } \\
\text { mal }\end{array}$} \\
\hline & D & $\begin{array}{l}D \\
6\end{array}$ & $\begin{array}{l}D \\
5\end{array}$ & $\begin{array}{l}D \\
4\end{array}$ & $\begin{array}{l}D \\
3\end{array}$ & D & $\begin{array}{l}D \\
1\end{array}$ & $\begin{array}{l}D \\
0\end{array}$ & \\
\hline 0,5 & 0 & 0 & 0 & 1 & 1 & 0 & 0 & 1 & 25 \\
\hline 1 & 0 & 0 & 1 & 1 & 0 & 0 & 1 & 0 & 50 \\
\hline 1,5 & 0 & 1 & 0 & 0 & 1 & 1 & 0 & 1 & 75 \\
\hline 2 & 0 & 1 & 1 & 0 & 0 & 1 & 0 & 0 & 100 \\
\hline 2,5 & 0 & 1 & 1 & 1 & 1 & 1 & 0 & 1 & 125 \\
\hline 3 & 1 & 0 & 0 & 1 & 0 & & 1 & 0 & 150 \\
\hline 3,5 & 1 & 0 & 1 & 0 & 1 & 1 & 1 & 1 & 175 \\
\hline 4 & 1 & 1 & 0 & 0 & 1 & 0 & 0 & 0 & 200 \\
\hline 4,5 & 1 & 1 & 0 & 1 & 0 & 1 & 0 & 1 & 225 \\
\hline 5 & 1 & 1 & 1 & 1 & 1 & 0 & 1 & 0 & 250 \\
\hline
\end{tabular}

Table 4. Hasil Perhitungan ADC 0804

Dilihat dari hasil perhitungan dengan hasil percobaan terdapat beberapa perbedaan hasil ouput yang didapat. Ini disebabkan beberapa hal antara lain adalah sebagai berikut :

- Kurang akurat input yang diberikan pada ADC, karena IC ini sangat sensitive terhadap input yang diberikan.

- Sensitifnya keluaran ADC karena percobaan yang dilakukan secara analog bukan secara digital.

- Perhitungan dengan percobaan yang dilakukan selalu tidak harus sama dan akurat, banyak factor penyebabnya antara lain human error, komponen yang kurang mendukung, pemasangan yang tidak sesuai dengan referensinya.

Berdasarkan persamaan diatas melalui perhitungan, bisa dikatakan bahwa setiap kenaikkan 0,02 V DC yang diberikan sebagai input masuk pada ADC. Maka output keluaran dalam bentuk decimal atau biner mengalami perubahan.

IC ADC 0804 apabila diberikan input melebihi dari 5 Volt DC maka IC akan terbakar dan apabila mendapatkan nilai input minus maka IC akan rusak Jadi pemakaian IC ADC 0804 sangatlah hati-hati baik dalam pemasanga ataupun dalam pengoperasiannya.

\section{Pengujian Digital Analog Converter 0808}

Untuk pengujian ADC 0808 dapat dilakukan dengan cara memberikan tegangan input yang konstan pada masukan data 8 bit yaitu memberikan tegangan sebesar $5 \mathrm{~V}$ DC. Sedangkan untuk mendapatkan hasil yang variable digunakan saklar pada tiap-tiap input masuk 8 bitnya. Untuk lebih jelasnya diperlihatkan pada gambar dibawah ini :

\begin{tabular}{|c|c|c|c|c|c|c|c|c|c|}
\hline \multirow{2}{*}{$\begin{array}{l}V_{V_{N}} \\
\text { (V) }\end{array}$} & \multicolumn{8}{|c|}{ Data Biner (Output DAC 0808) } & \multirow{2}{*}{$\begin{array}{l}V_{0} \\
\text { (V) }\end{array}$} \\
\hline & A8 & A7 & A6 & A5 & $\mathrm{A} 4$ & $\mathrm{~A} 3$ & $\mathrm{~A} 2$ & A1 & \\
\hline 5 & 0 & 0 & 0 & 0 & 0 & 0 & 0 & 1 & 5 \\
\hline 5 & 0 & 0 & 0 & 0 & 0 & 0 & 1 & 0 & 2,5 \\
\hline 5 & 0 & 0 & 0 & 0 & 0 & 1 & 0 & 0 & 1,2 \\
\hline 5 & 0 & 0 & 0 & 0 & 1 & 0 & 0 & 0 & $\begin{array}{l}0,6 \\
25 \\
\end{array}$ \\
\hline
\end{tabular}

Table 5. Data Pengujian DAC 0808

Bila dibandingkan dengan hasil perhitungan yang dilakukan sama dengan hasil pengukuran dengan mengggunakan persamaan dibawah ini :

$$
V_{\text {out }}=\operatorname{Vref}\left(\frac{A_{1}}{2}+\frac{A_{2}}{4}+\frac{A_{3}}{8}+\frac{A_{4}}{16}+\frac{A_{5}}{32}+\frac{A_{6}}{64}+\frac{A_{7}}{128}+\frac{A_{8}}{256}\right)
$$

\section{Pengujian Driver (Actuator)}

Untuk pengujian driver yang digunakan sebagai penggerak adalah mengetahui daya mampu dari transistor yang dipakai untuk dapat menggerakan motor berdaya besar. 
Pengujian Program Pengendali

Hasil pengujian pengendali dapat dilihat pada table berikut :

Tabel 5. Data Pengukuran Pengontrolan PID

\begin{tabular}{|c|c|c|c|c|c|}
\hline \multirow{2}{*}{ No. } & \multirow{2}{*}{$\begin{array}{l}\mathbf{V}_{\text {REF }} \\
(\mathbf{r p m})\end{array}$} & \multicolumn{3}{|c|}{$\begin{array}{c}\text { Parameter } \\
\text { PID }\end{array}$} & \multirow{2}{*}{$\begin{array}{c}\text { Set } \\
\text { Point }\end{array}$} \\
\cline { 3 - 6 } & $\mathbf{K p}$ & $\mathbf{K i}$ & Kd & $\mathbf{( V )}$ \\
\hline \hline 1 & 1458 & 20 & 0.5 & 2 & 3.5 \\
\hline 2 & 1562 & 30 & 5 & 1 & 3.5 \\
\hline 3 & 1623 & 40 & 10 & 0.5 & 3.5 \\
\hline
\end{tabular}

Pada plot grafik pertama dengan nilai $\mathrm{Kp}=20, \mathrm{Ki}=0.5$ dan $\mathrm{Kd}=2$, menghasilkan suatu reaksi sistem terhadap pengendali yang stabil, respon cepat serta steady state yang kecil. Integral Controller memiliki karakteristik mengurangi rise time, menambah overshoot dan settling time serta menghilangkan steady state error sedangkan konstanta derivative controller adalah untuk memperbaiki overshoot.

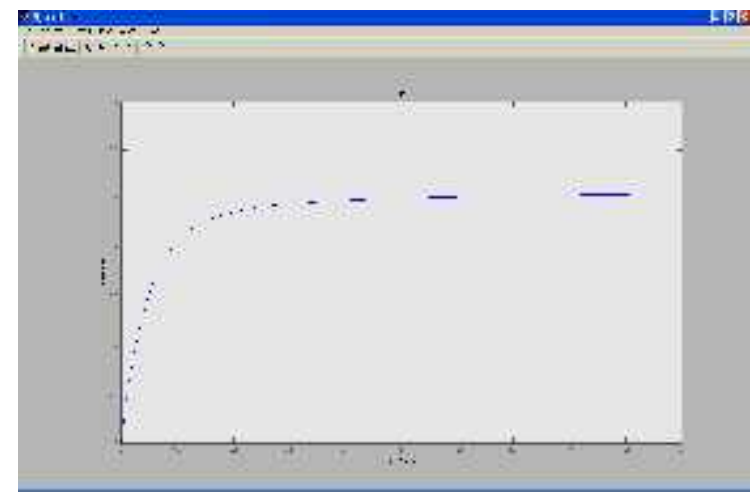

Gambar 8. Grafik Pengujian PID dengan $\mathrm{Kp}=20, \mathrm{Ki}=0.5, \mathrm{Kd}=2$

Sedangkan untuk plot grafik kedua dengan nilai $\mathrm{Kp}=40, \mathrm{Ki}=10$ dan $\mathrm{Kd}=$ 0.5 , menghasilkan suatu reaksi sistem oleh pengendali yang terjadi adalah adanya overshoot dan adanya steady state error. Penambahan nilai konstanta $\mathrm{Kp}$ menimbulkan kenaikkan overshoot namun dapat mengurangi rise time. Konstanta Kp berbanding lurus terhadap settling time. Karena $\mathrm{Kp}>\mathrm{Ki}$, maka steady state errornya tidak dapat dihilangkan.

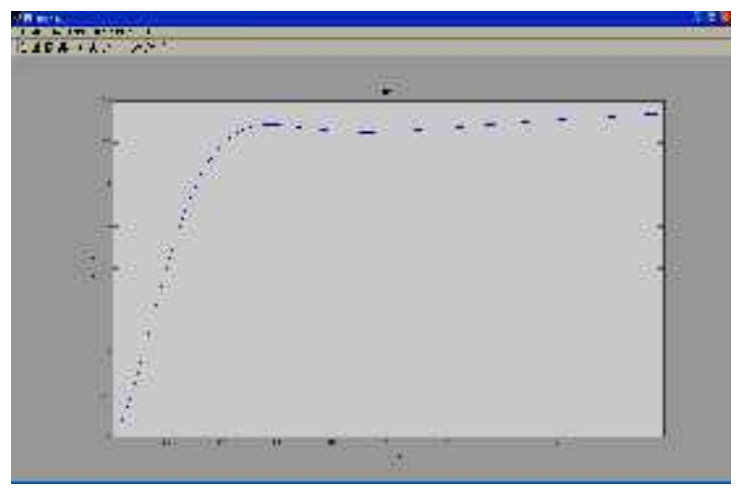

Gambar 9. Grafik pengujian PID dengan $\mathrm{Kp}=40, \mathrm{Ki}=10, \mathrm{Kd}=0.5$

\section{KESIMPULAN}

Berdasarkan uraian-uraian pada babbab terdahulu maka hasil penelitian ini dapat disimpulkan sebagai berikut:

1. Pengendali Analog

- Untuk memasukan sinyal analog yang berasal dari tachogenerator ke PC digunakan ADC 0804, dengan kelebihan menghasilkan 8 bit keluaran

- Untuk meneruskan sinyal keluaran 8 bit menjadi analog digunakan DAC 0808, kelebihannya mempunyai fasilitas chip select untuk memilih input yang diinginkan

- Interfaceyang digunakan untuk menghubungkan keduanya (ADC dan DAC) digunakan Paralel port

2. Pengendali PID digital

- Nilai-nilai konstanta Kp, Ki, Kd diperoleh melalui uji coba trial and error, untuk memdapatkan respon kendali sesuai keinginan.

- Kontrol P digunakan untuk memperbaiki waktu naik (rise time), Kontrol I untuk menghilangkan kesalahan keadaan mantap (steady state error), sedangkan control D digunakan untuk memperbaiki lonjakan lebih (overshoot\}. 
3. Pengendali Logika Fuzzy

- Pengendali logika fuzzy melalui tahapan sebagai berikut;

- Fuzzyfikasi yaitu merubah variabel numerik kedalam variabel fuzzy dengan cara memberi tingkat kwantisasi fungsi keanggotaan dan derajat keanggotaan.

Aturan fuzzy yaitu jika masukan adalah A dan B maka keluaran adalah $\mathrm{C}$ dan seterusnya.

- Defuzzyfikasi yaitu membalikkan variabel linguistic (fuzzy) ke variabel numerik (non fuzzy) dari masukan dan keluaran dengan menggunakan rumus Centre of area (COA).

- Penggunaan kendali logika fuzzy pada sistem pengaturan kecepatan menghasil-kan perubahan yang cepat untuk mencapai steady state tanpa mengalami transient.

- Sinyal kendali yang dihasilkan lebih kecil 10\% dari set-point, apabila setpoint yang dimasukan tidak sama dengan nilai membership function..

- Penggunaan kendali logika fuzzy tetap beracuan pada kendali konvensional yang sudah dirancang sebelumnya.

\section{Saran-Saran}

1. Untuk men-drive motor-motor berdaya besar sebaiknya gunakan komponen TRIAC, atau MOSFET

2. Untuk mendapatkan sinyal umpan balik yang lebih besar sebaiknya gunakan sensor dengan output sinyal [dynamo ] yang lebih besar

3. Akan lebih baik apabila setiap kali percobaan dapat menampilkan hasil perubahan variabel fuzzy yakni membership function dan aturanaturan fuzzy dilayar monitor.

4. Metoda kendali PID-Fuzzy sangat sesuai digunakan untuk mengendalikan plant statis dan plant dinamis

\section{DAFTAR PUSTAKA}

Berlian, Yayan Iyan., 1998, Sensor dan Transduser, Bandung : Diktat Kuliah Elektro ITB

Cooper, William D., 1993. Intrumentasi Elektronik dan Teknik Pengukurn. Jakarta : Erlangga

Jacob, J. Michael., 1995.Industrial Control Electronics, Application and Design. Singapore : Prentice Hall International Inc,

Johnson, Curtis D., 1997. Process Control Instrumentation Technology, Singapore:Prentice Hall International Inc

Ohba, Ryoji., 1992. Intelligent Sensor Technology, Singapore : John Willey $\&$ Sons

Ogata, K., 1991. Teknik Kontrol Otomatik. Jakarta :Erlangga

Roswaldi Sk., Mooduto, H.A., Kartika, 2000. Rancang bangun Sitem Pengendali Level Cairan Menggunakan Metoda kendali PID digital dan Logika Fuzzy, Politeknik Negeri Padang : Hasil penelitian

Roswaldi Sk., Aida, Zass Ressy., 2003. Rancangbangun Modul Kendali PID Analog Dengan Implementasi Pada Pengaturan Kecepatan Putaran Motor DC. Politeknik Negeri Padang : Hasil penelitian

Smith, Carlos A., Corripio, Amando B.,1985. Principles and Practice of Automatic Process Control, Singapore, John Willey \& Son

Sharon, D., dkk, 1982. Robot dan Otomasi Industri.Jakarta:Elex Media Komputindo

Zuhal, 1980. Dasar Tenaga Listrik Bandung : Penerbit ITB 
ISSN: 2085-6989 
ISSN: 2085-6989 